\title{
Practitioners Preference and Criteria on Deciding the Surgical Technique of Implant Placement in Riyadh, Saudi Arabia: Flap vs. Flapless Techniques
} \author{
Sara AlFaqeeh ${ }^{3}$ \\ ${ }^{1}$ Preventive Department, Riyadh Elm University, Saudi Arabia \\ ${ }^{2}$ Dental Intern, Riyadh Elm University, Saudi Arabia \\ ${ }^{3}$ Dental Student, Riyadh Elm University, Saudi Arabia
}

Rakan Shaheen ${ }^{1 *}$, Abdullah AlFaqeeh², Faisal Bin Dawoad ${ }^{2}$ and

\section{Research Article \\ Volume 3 Issue 4}

Received Date: November 23, 2018

Published Date: December 06, 2018

DOI: 10.23880 /oajds- 16000208

*Corresponding author: Rakan Shaheen, Preventive Department, College of Dentistry, Riyadh Elm University, Riyadh 11681, Saudi Arabia, P.O. Box 84891, Tel: +966507172056; Email: rakan.s.shaheen@gmail.com

\section{Abstract}

Introduction: Dental implants placement has become an established treatment modality to replace missing teeth in Saudi Arabia with high success rates. And with the evolution in the surgical techniques; the practitioners and patients are looking for simpler and less traumatic surgical techniques.

Methodology: An online questionnaire form was distributed to the practitioners that perform dental implant therapy in Riyadh, Saudi Arabia. It was distributed by Google forms using convenience sampling. The encoding of the answers was done using Microsoft Excel and statistical analysis was done using the 22nd version of SPSS. The frequencies of the submitted data were measured using the mode and median for the nominal and ordinal variables respectively and the correlations between the different variables was done using the Chi-square test.

Results: 45 practitioners participated in the study. 14 were from the governmental sector and 31 from the private. The specialists were the highest group to participate. Between the flap and flapless techniques; 29 (64.4\%) preferred the flap technique over the flapless technique which was preferred by 16 (35.6\%). 86.7\% perform clinical intraoral measurements and $82.2 \%$ request CBCT Scans. The majority of participants 36 (80.1\%) felt comfortable performing a flapless technique surgery when the width of the bone at the implant site was $6 \mathrm{~mm}$ or more. The top advantage by 15 $(33.3 \%)$ was that it reduces trauma to the patient.

Conclusion: With the choice of the flapless surgical technique; the frequency of requesting CBCTs and surgical guides increases, the practitioners feel confident using the flapless technique for single implant placement and to avoid hemorrhagic tendencies of patients on anti-coagulants, and the main advantage observed by the practitioners is the 


\section{Open Access Journal of Dental Sciences}

reduced trauma to the patient, overall the flap surgical technique is still preferred by the practitioners over the flapless technique.

Keywords: Dental implants; Surgical techniques; Chi-square test; Flap technique; Flapless technique

\section{Introduction}

Dental implants placement has become an established treatment modality to replace missing teeth in Saudi Arabia with high success rates [1]. And with the evolution in the surgical techniques; the practitioners and patients are looking for simpler and less traumatic surgical techniques. The conventional method of implant placement is the flap surgical technique where the surgeon reflects a full thickness mucoperiosteal flap to expose the bone, this method has multiple advantages and disadvantages. The direct visualization of the implant site, the reduced risk of fenestrations and dehiscences during the implant placement and the ability to manipulate the soft tissue to the desired dimensions are some of the advantages of the flap surgical technique $[2,3]$. On the other hand, the detachment of the periosteum due to the flap reflection can lead to decrease in the blood supply to the bone around the implant site and the patient's discomfort after the surgical procedure (pain, edema, bleeding) and the need to place sutures after the implant placement are some of its disadvantages $[4,5]$.

The use of the flapless surgical technique is gaining more popularity in the recent years due to its theoretical advantages [5]. As it's a less traumatic surgical procedure, the patient's discomfort is reduced and the loss of the soft tissues and bone around the implant is also reduced [6]. The main drawback of the flapless technique is the minimal exposure of bone at the implant placement site which presents a greater risk of bone perforation at the buccal or lingual cortical plates [7]. Therefore, the flapless implant placement surgical procedure requires advanced investigation methods and clinical experience in order to avoid such complications [8].

The aim of this study is to survey the preferred surgical method for implant placement by the practitioners and the criteria that they rely on to choose a flap or flapless surgical technique.

\section{Materials and Methods}

A questionnaire was designed to assess the preference to assess different aspects related to the patient and the practitioner based on the literature review. Its validity and understand ability were then tested on 5 subjects, then its reliability was tested on 20 subjects with a oneweek gap between the two responses and it was found reliable. The questionnaire was then distributed online using Google Forms ${ }^{\mathrm{TM}}$ to the practitioners that perform dental implant surgeries in Riyadh, Saudi Arabia.

The Saudi Arabian ministry of health (MOH) doesn't have citable specific date on the dentists practicing dental implant placement surgeries in the city of Riyadh, but it does have the number of the dental practitioners in the whole Riyadh region at 4685 practitioners KoSA M.O.H. [9], assuming that half of them are practicing dental implant placement surgeries; the population proportion was set to 0.029 based on the Saudi Arabian general authority of statistics' data for the Riyadh region's population KoSA G.a.S [10]. The sample size was calculated using a confidence level of 95\%, the aforementioned population proportion and a margin of error (confidence interval) of 0.05 , and the result was 43 . The questionnaire was answered by 45 practitioners in Riyadh city that perform dental implant placement surgeries using the convenience sampling method. The encoding of the answers was done using Microsoft Excel $^{\mathrm{TM}}$ and statistical analysis was done using the 22 nd version of SPSS ${ }^{\mathrm{TM}}$. The frequencies of the submitted data were measured using the mode and median for the nominal and ordinal variables respectively and the correlations between the different variables were done using the Chisquare test.

\section{Results}

The questionnaire was distributed to 70 practitioners who perform implant placement surgeries, 45 practitioners participated. Analyzing the participants revealed that $39(86.7 \%)$ participants were males and 6 $(13.3 \%)$ were females. $14(31.1 \%)$ were from the governmental sector and 31 (68.9\%) from the private sector. The specialists were the highest group to participate at $21(46.7 \%)$ followed by the consultants at $14(31.1 \%)$ and the general practitioners at $10(22.2 \%)$. $13(28.9 \%)$ of the participants were Periodontists, 8 $(17.8 \%)$ were Implantologists, $6(13.3 \%)$ were oral and maxillofacial surgeons, 5 (11.1\%) were Prosthodontists, general practitioners, advanced general practitioners and 
Restorative dentists were at $4(8.9 \%)$ each, and $1(2.2 \%)$ was an oral surgeon. The highest participating group in regard to years of experience was tied between (1 to 3 years) and (more than 10 years) at 15 (33.3\%) participants in each group, $9(20 \%)$ had 5 to 10 years of experience and $6(13.3 \%)$ had 3 to 5 years. $26(57.8 \%)$ participants place 1 to 3 implants per week, 9 (20\%) place 3 to 5 implants, $6(13.3 \%)$ place more than 10 implants and $4(8.9 \%)$ place 5 to 10 implants per week. 26 (57.8) participants also perform the prosthetic part of the implant therapy and 19 (42.2\%) don't. And when asked about their preference between the flap and flapless techniques; 29 (64.4\%) preferred the flap technique over the flapless technique which preferred by 16 (35.6\%) (Table 1).

\begin{tabular}{|c|c|c|c|}
\hline & & $\mathbf{N}$ & Percentage \\
\hline \multirow{2}{*}{ Gender } & Male & 39 & $86.70 \%$ \\
\hline & Female & 6 & $13.30 \%$ \\
\hline \multirow{2}{*}{ Sector } & Governmental & 14 & $31.10 \%$ \\
\hline & Private & 31 & $68.90 \%$ \\
\hline \multirow{3}{*}{ Clinical Position } & General Practitioner & 10 & $22.20 \%$ \\
\hline & Specialist & 21 & $46.70 \%$ \\
\hline & Consultant & 14 & $31.10 \%$ \\
\hline \multirow{8}{*}{ Specialty Field } & General Practitioner & 4 & $8.90 \%$ \\
\hline & Advanced General Practitioner & 4 & $8.90 \%$ \\
\hline & Periodontist & 13 & $28.90 \%$ \\
\hline & Implantologist & 8 & $17.80 \%$ \\
\hline & Oral Surgeon & 1 & $2.20 \%$ \\
\hline & Oral \& Maxillofacial Surgeon & 6 & $13.30 \%$ \\
\hline & Prosthodontist & 5 & $11.10 \%$ \\
\hline & Restorative Dentist & 4 & $8.90 \%$ \\
\hline \multirow{4}{*}{ Year of Experience } & 1 to 3 Years & 15 & $33.35 \%$ \\
\hline & 3 to 5 Years & 6 & $13.35 \%$ \\
\hline & 5 to 10 Years & 9 & $20.00 \%$ \\
\hline & $>10$ Years & 15 & $33.30 \%$ \\
\hline \multirow{4}{*}{ Implants Placed Per Week } & 1 to 3 Implants & 26 & $57.80 \%$ \\
\hline & 3 to 5 Implants & 9 & $20.00 \%$ \\
\hline & 5 to 10 Implants & 4 & $8.90 \%$ \\
\hline & $>10$ Implants & 6 & $13.30 \%$ \\
\hline \multirow{2}{*}{ Place the Implant's Prosthesis } & Yes & 26 & $57.80 \%$ \\
\hline & No & 19 & $42.20 \%$ \\
\hline
\end{tabular}

Table 1: General Data on the Practitioners.

Taking a deeper look into each section of the given data revealed the following:

\section{Preference Based on a Specific Patient Scenario}

The majority of participants $36 \quad(80.1 \%)$ felt comfortable performing a flapless technique surgery when the width of the bone at the implant site was $6 \mathrm{~mm}$ or more (Figure 1). In regard to the location of the implant to be placed; the majority preferred the flap technique for all the locations. The preferences changed when the focus was on the medical condition of the patient where the flap technique was preferred for the diabetic and hypertensive patients, the flapless was preferred for the patients on anti-coagulant therapy, while the refusal to treat was the top response for the medically compromised patients and the top two responses equally were the refusal to treat and the condition doesn't affect the choice of surgical technique for the infectious patients. The agreement was shown again when the patient's age and gender were the focus, as the majority preferred the flap technique for all age groups, and the majority declared that the gender has no effect on the choice of surgical technique. As to the amount of keratinized gingiva, the flap technique was the 
preferred method when the keratinized was $4 \mathrm{~mm}$ or less and remained even at $5 \mathrm{~mm}$ or more, but the flapless technique preference started to rise at more than $5 \mathrm{~mm}$ of keratinization going from $17.8 \%$ in the 1 to $2 \mathrm{~mm}$ group to $24.4 \%$ in the more than $5 \mathrm{~mm}$ group. Finally, for multiple implants placement and over dentures the preference was for the flap technique, while for single implant placement the highest preference was for the flapless technique (Tables $2 \& 3$ ).

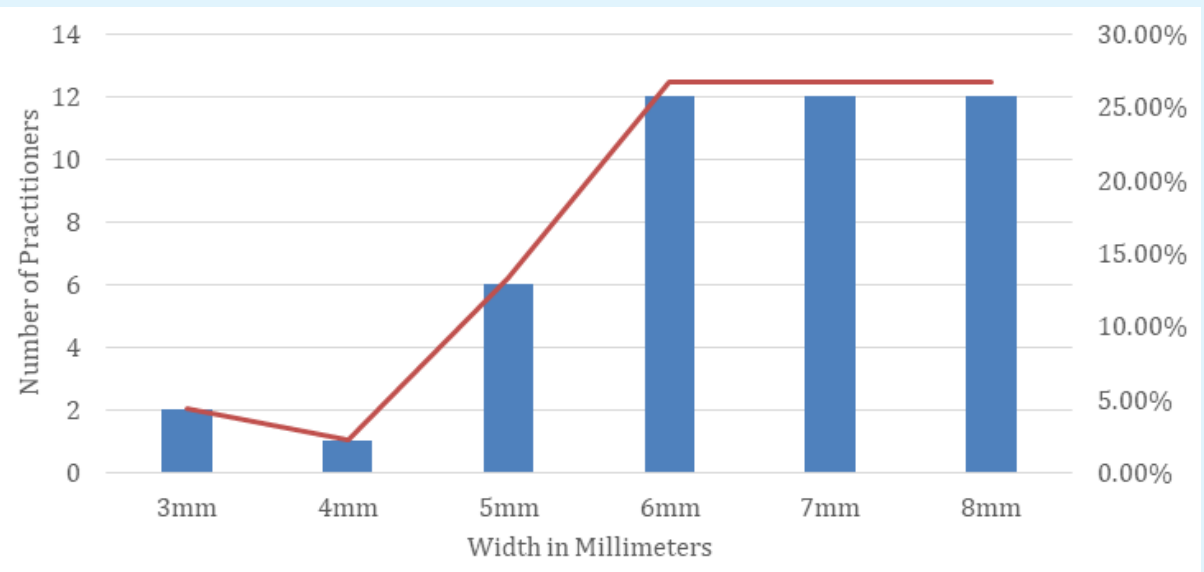

Figure 1: Ridge's Width on Deciding to Choose the Flapless Technique.

\begin{tabular}{|c|c|c|c|}
\hline & & $\mathbf{N}$ & Percentage \\
\hline \multirow{4}{*}{ Young Patients } & Flap Technique & 18 & $40.00 \%$ \\
\hline & Flapless Technique & 9 & $20.00 \%$ \\
\hline & Doesn't Affect the Choice & 13 & $28.90 \%$ \\
\hline & I Don't Treat & 5 & $11.10 \%$ \\
\hline \multirow{3}{*}{ Middle-Aged Patients } & Flap Technique & 21 & $46.70 \%$ \\
\hline & Flapless Technique & 8 & $17.80 \%$ \\
\hline & Doesn't Affect the Choice & 16 & $35.60 \%$ \\
\hline \multirow{4}{*}{ Elderly Patients } & Flap Technique & 21 & $46.70 \%$ \\
\hline & Flapless Technique & 10 & $22.20 \%$ \\
\hline & Doesn't Affect the Choice & 12 & $26.70 \%$ \\
\hline & I Don't Treat & 2 & $4.40 \%$ \\
\hline \multirow{3}{*}{ Male Patients } & Flap Technique & 18 & $40.00 \%$ \\
\hline & Flapless Technique & 4 & $8.90 \%$ \\
\hline & Doesn't Affect the Choice & 23 & $51.10 \%$ \\
\hline \multirow{3}{*}{ Female Patients } & Flap Technique & 18 & $40.0 \% \%$ \\
\hline & Flapless Technique & 4 & $8.90 \%$ \\
\hline & Doesn't Affect the Choice & 23 & $51.10 \%$ \\
\hline \multirow{4}{*}{ Diabetic Patients } & Flap Technique & 16 & $35.60 \%$ \\
\hline & Flapless Technique & 13 & $28.90 \%$ \\
\hline & Doesn't Affect the Choice & 12 & $26.70 \%$ \\
\hline & I Don't Treat & 4 & $8.90 \%$ \\
\hline \multirow{4}{*}{ Hypertensive Patients } & Flap Technique & 15 & $33.30 \%$ \\
\hline & Flapless Technique & 13 & $28.90 \%$ \\
\hline & Doesn't Affect the Choice & 14 & $31.10 \%$ \\
\hline & I Don't Treat & 3 & $6.70 \%$ \\
\hline
\end{tabular}




\begin{tabular}{|c|c|c|c|}
\hline \multirow{4}{*}{ Patients on Anti-Coagulants } & Flap Technique & 10 & $22.20 \%$ \\
\cline { 2 - 3 } & Flapless Technique & 21 & $46.70 \%$ \\
\cline { 2 - 3 } & Doesn't Affect the Choice & 8 & $17.80 \%$ \\
\cline { 2 - 3 } & I Don't Treat & 6 & $13.30 \%$ \\
\hline \multirow{3}{*}{ Medically Compromised Patients } & Flap Technique & 10 & $22.20 \%$ \\
\cline { 2 - 3 } & Flapless Technique & 6 & $13.30 \%$ \\
\cline { 2 - 3 } & Doesn't Affect the Choice & 9 & $20.00 \%$ \\
\cline { 2 - 3 } & I Don't Treat & 20 & $44.40 \%$ \\
\hline \multirow{3}{*}{ Patients with Infectious Diseases } & Flap Technique & 11 & $24.40 \%$ \\
\cline { 2 - 3 } & Flapless Technique & 12 & $22.20 \%$ \\
\cline { 2 - 3 } & Doesn't Affect the Choice & 12 & $26.70 \%$ \\
\cline { 2 - 3 } & I Don't Treat & $12.70 \%$ \\
\hline
\end{tabular}

Table 2: Technique Preference Based on the Patient's Status.

\begin{tabular}{|c|c|c|c|}
\hline & & $\mathbf{N}$ & Percentage \\
\hline \multirow{3}{*}{ Anterior Maxilla } & Flap Technique & 29 & $64.40 \%$ \\
\hline & Flapless Technique & 8 & $17.80 \%$ \\
\hline & Doesn't Affect the Choice & 8 & $17.80 \%$ \\
\hline \multirow{3}{*}{ Anterior Mandible } & Flap Technique & 31 & $68.90 \%$ \\
\hline & Flapless Technique & 8 & $17.80 \%$ \\
\hline & Doesn't Affect the Choice & 6 & $13.30 \%$ \\
\hline \multirow{3}{*}{ Posterior Maxilla } & Flap Technique & 28 & $62.20 \%$ \\
\hline & Flapless Technique & 10 & $22.20 \%$ \\
\hline & Doesn't Affect the Choice & 7 & $15.60 \%$ \\
\hline \multirow{3}{*}{ Posterior Mandible } & Flap Technique & 26 & $57.80 \%$ \\
\hline & Flapless Technique & 11 & $24.40 \%$ \\
\hline & Doesn't Affect the Choice & 8 & $17.80 \%$ \\
\hline \multirow{3}{*}{1 to $2 \mathrm{~mm}$ Keratinized Gingiva } & Flap Technique & 28 & $62.20 \%$ \\
\hline & Flapless Technique & 8 & $17.80 \%$ \\
\hline & Doesn't Affect the Choice & 9 & $20.00 \%$ \\
\hline \multirow{3}{*}{3 to $5 \mathrm{~mm}$ Keratinized Gingiva } & Flap Technique & 23 & $51.10 \%$ \\
\hline & Flapless Technique & 10 & $22.20 \%$ \\
\hline & Doesn't Affect the Choice & 12 & $26.70 \%$ \\
\hline \multirow{3}{*}{ > 5 mm Keratinized Gingiva } & Flap Technique & 21 & $46.70 \%$ \\
\hline & Flapless Technique & 11 & $24.40 \%$ \\
\hline & Doesn't Affect the Choice & 13 & $28.90 \%$ \\
\hline \multirow{3}{*}{ Single Implant } & Flap Technique & 15 & $33.30 \%$ \\
\hline & Flapless Technique & 18 & $40.00 \%$ \\
\hline & Doesn't Affect the Choice & 12 & $26.70 \%$ \\
\hline \multirow{3}{*}{ Multiple Implants } & Flap Technique & 29 & $64.40 \%$ \\
\hline & Flapless Technique & 4 & $8.90 \%$ \\
\hline & Doesn't Affect the Choice & 12 & $26.70 \%$ \\
\hline \multirow{3}{*}{ Implants for an Over denture } & Flap Technique & 26 & $57.80 \%$ \\
\hline & Flapless Technique & 5 & $11.10 \%$ \\
\hline & Doesn't Affect the Choice & 14 & $31.10 \%$ \\
\hline
\end{tabular}

Table 3: Technique Preference Based on the Edentulous Area.

\section{Preference Based on the Practitioner}

Between males and females, the flap technique was preferred by $26(66.7 \%)$ males and $3(50 \%)$ females.
Based on the sector, the governmental practitioners highly preferred the flap technique at $13(92.9 \%)$ and $\mathrm{P}<$ 0.5 , while the private sector was almost split in half between flap and flapless with $16(51.6 \%)$ and 15 
(48.4\%) respectively. The general practitioners, the specialists and the consultants all preferred the flap technique at 6 (60\%), $14(66.7 \%)$ and 9 (64.4\%) respectively. The advanced general practitioners and Prosthodontists were the only specialties that preferred the flapless technique at $3(75 \%)$ and $3(60 \%)$ respectively. Most of the (years of experience) groups preferred the flap technique except the (3 to 5 years) group, also most of the (implants placed weekly) groups preferred the flap technique except the (5 to 10 implants) groups and finally the practitioners who perform the prosthetic part of the implant therapy also preferred the flap technique at $16(61.5 \%)$. The chi-square test showed no statistical significance between all the groups $(\mathrm{P}>0.5)$ (Table 4).

\begin{tabular}{|c|c|c|c|c|c|c|}
\hline & & \multicolumn{2}{|c|}{ Flap } & \multicolumn{2}{|c|}{ Flapless } & \multirow{2}{*}{ Sig. } \\
\hline & & $\mathbf{N}$ & $\%$ & $\mathbf{N}$ & $\%$ & \\
\hline \multirow{2}{*}{ Gender of Practitioner } & Male & 26 & $66.70 \%$ & 13 & $33.30 \%$ & \multirow{2}{*}{0.427} \\
\hline & Female & 3 & $50 \%$ & 3 & $50 \%$ & \\
\hline \multirow{2}{*}{ Sector } & Governmental & 13 & $92.90 \%$ & 1 & $7.10 \%$ & \multirow{2}{*}{$0.007^{*}$} \\
\hline & Private & 16 & $51.60 \%$ & 15 & $48.40 \%$ & \\
\hline \multirow{3}{*}{ Clinical Position } & General Practitioner & 6 & $60.00 \%$ & 4 & $40.00 \%$ & \multirow{3}{*}{0.936} \\
\hline & Specialist & 14 & $66.70 \%$ & 7 & $33.30 \%$ & \\
\hline & Consultant & 9 & $64.30 \%$ & 5 & $35.70 \%$ & \\
\hline \multirow{8}{*}{ Specialty Field } & General Practitioner & 3 & $75.00 \%$ & 1 & $25.00 \%$ & \multirow{8}{*}{0.27} \\
\hline & $\begin{array}{l}\text { Advanced General } \\
\text { Practitioner }\end{array}$ & 1 & $25.00 \%$ & 3 & $75.00 \%$ & \\
\hline & Periodontist & 9 & $69.20 \%$ & 4 & $30.80 \%$ & \\
\hline & Implantologist & 4 & $50.00 \%$ & 4 & $50.00 \%$ & \\
\hline & Oral Surgeon & 1 & $100 \%$ & 0 & $0.00 \%$ & \\
\hline & $\begin{array}{c}\text { Oral \& Maxillofacial } \\
\text { Surgeon }\end{array}$ & 5 & $83.30 \%$ & 1 & $16.70 \%$ & \\
\hline & Prosthodontist & 2 & $40.00 \%$ & 3 & $60.00 \%$ & \\
\hline & Restorative Dentist & 4 & $100.00 \%$ & 0 & $0.00 \%$ & \\
\hline \multirow{4}{*}{ Years of Experience } & 1 to 3 Years & 10 & $66.70 \%$ & 5 & $33.30 \%$ & \multirow{4}{*}{0.376} \\
\hline & 3 to 5 Years & 2 & $33.30 \%$ & 4 & $66.70 \%$ & \\
\hline & 5 to 10 Years & 6 & $66.70 \%$ & 3 & $33.30 \%$ & \\
\hline & $>10$ Years & 11 & $73.30 \%$ & 4 & $26.70 \%$ & \\
\hline \multirow{4}{*}{$\begin{array}{c}\text { Implants Placed Per } \\
\text { Week }\end{array}$} & 1 to 3 Implants & 15 & $57.70 \%$ & 11 & $42.30 \%$ & \multirow{4}{*}{0.065} \\
\hline & 3 to 5 Implants & 7 & $77.80 \%$ & 2 & $22.20 \%$ & \\
\hline & 5 to 10 Implants & 1 & $25.00 \%$ & 3 & $75.00 \%$ & \\
\hline & $>10$ Implants & 6 & $100.00 \%$ & 0 & $0.00 \%$ & \\
\hline \multirow{2}{*}{$\begin{array}{l}\text { Place the Implant's } \\
\text { Prosthesis }\end{array}$} & Yes & 16 & $61.50 \%$ & 10 & $38.50 \%$ & \multirow{2}{*}{0.634} \\
\hline & No & 13 & $68.40 \%$ & 6 & $31.60 \%$ & \\
\hline
\end{tabular}

Table 4: Technique Preference Based on the Practitioner's Status.

\section{Main Advantage of the Flapless Technique}

When asked about the main advantage of the flapless technique over the flap technique in the implant placement surgery, $15(33.3 \%)$ find that it reduces trauma to the patient represented by $27.6 \%$ of the practitioners who prefer the flap technique and $43.8 \%$ of the practitioners who prefer the flapless technique. 10 $(22.2 \%)$ find that it preserves the blood supply to the bone around the implant, 7 (15.6\%) find that it results in better soft tissue profile around the implant, 4 (8.9\%) find that it reduces the operating time and $2(4.4 \%)$ find that it doesn't require suturing of the surgical site. While 7 $(15.6 \%)$ find that the flapless technique has no advantage over the flap technique, all the 7 are practitioners who prefer the flap technique. The chi-square test showed a statistical significance between the groups $(\mathrm{P}<0.5)$ (Figure 2). 


\section{Open Access Journal of Dental Sciences}

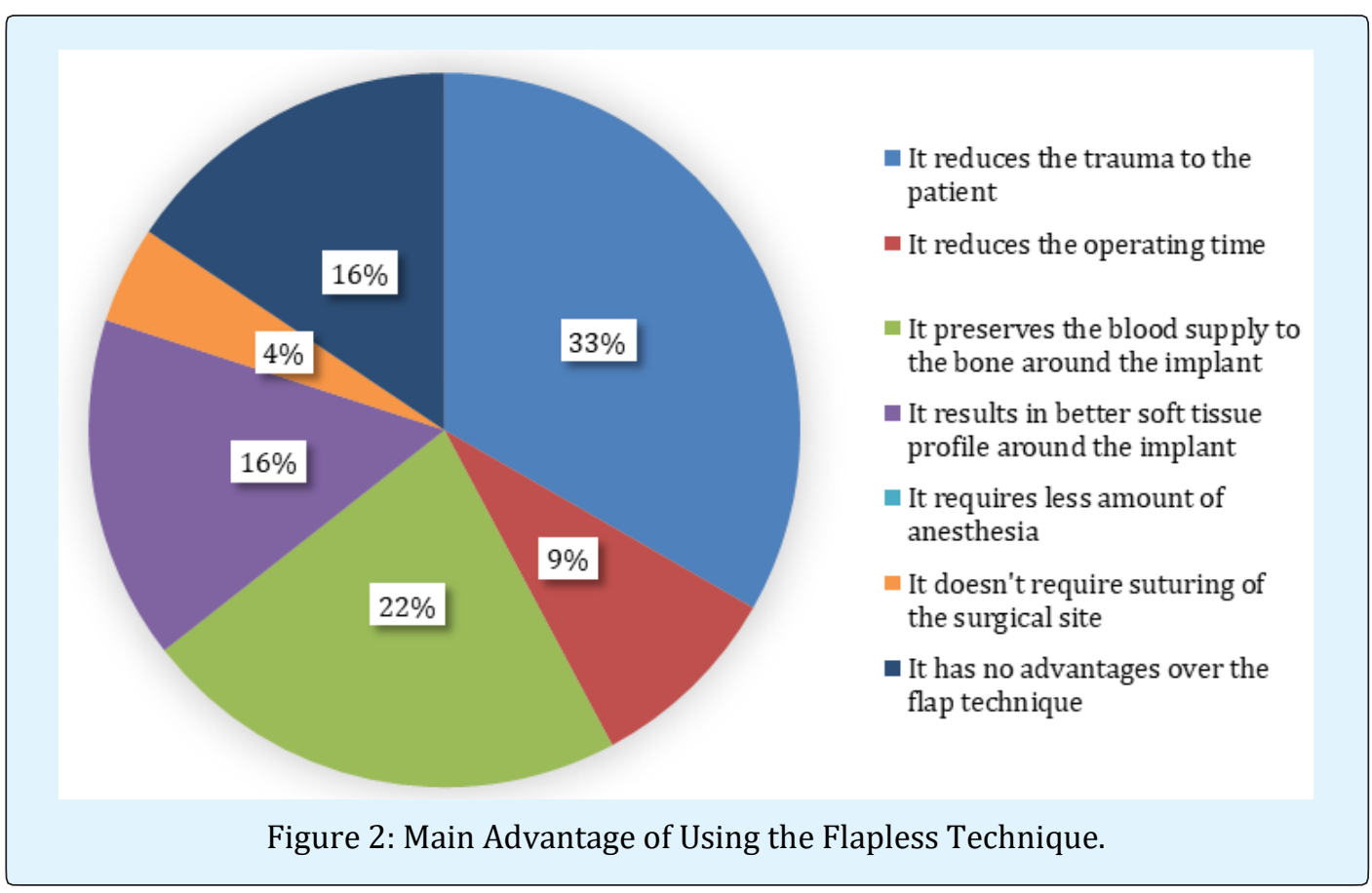

\section{Discussion}

The advantages and disadvantages of each technique alongside the expertise variability of the sample between governmental and private, years of experience, field of specialty and frequency of implant placement surgeries per week have yielded some opinion variety amongst this study's sample. As $93 \%$ of the practitioners believe that the flapless technique has various advantages over the flap technique; it seemed that the preference would be to use the flapless technique as was observed by Pisoni, et al. [5], but when asked directly about their preference the majority at $64.4 \%$ preferred the flap technique which can be due to the practitioners fear of the wide-spread vitamin $\mathrm{D}$ deficiency that can affect the bone remodelling after extraction and that was reported to be $87.8 \%$ in Saudi Arabia by Ardawi, et al. [11] or due to the high prevalence of osteopenia in the Saudi population as reported to be 18 to $41 \%$ by Ghannam, et al. [12].

The practitioners were comfortable performing a flap technique surgery for diabetic and hypertensive patients which follows the finding presented by Ramalingam, et al. [13] in their study where they found that the majority perceived all the medical conditions other than diabetes and hypertension to be contraindications for implant surgery. Pani, et al. [14] studied the willingness to treat patients with various medical conditions and found that it was significantly decreased when the medical conditions in question were HIV infections and acquired immunodeficiency syndrome (AIDS), which was also shown in the practitioners' responses where the refusal to treat infectious patients was the top answer.

As for patients taking anti-coagulants; the flapless technique felt like the safer choice for the majority of the practitioners which could be due to the increased postoperative bleeding risk for these patients as stated by Shi, et al. [15], but they also stated that the implant placement surgeries didn't have any increase in the post-operative bleeding tendencies for the patients on anti-coagulants. While the study by Zoman, et al. [16] suggested the flapless technique for the patients on long-term anticoagulants without interrupting the daily dosage.

When the field of specialty, the year of experience, the clinical position and the number of implant surgeries weekly were highlighted; it showed the favoring of the flap technique by most of the groups, but the study by Van de Velde, et al. [17] showed no difference between the experiences, the specialty, the clinical position and the weekly implants' numbers when performing the flapless technique in vitro, where they found that the deviation in the implant's angle was statistically significant in all the groups regardless of any factors, which can point out the practitioners' confidence in using the flap technique as one of the reasons for preferring it over the flapless one.

The effect of the amount of keratinized gingiva in the preference of the practitioner wasn't strong as the 


\section{Open Access Journal of Dental Sciences}

majority preferred the flap technique, but it was observed that with an increased amount of keratinized gingiva the practitioners started to lean toward the flapless technique. Which could be due to the fear of losing the keratinized gingiva during the tissue punching in the flapless technique surgeries as stated by Wang, et al. [18], but that study also found that the flapless technique has the potential to preserve the keratinized gingiva over the flap technique and that the fear of losing it due to the tissue punching has no merit, and the review by LlamasMonteagudo, et al. [19] stated that the flap technique had a greater loss of keratinized gingiva. Also, the study by Wang, et al. states that $6 \mathrm{~mm}$ of crestal bone width is adequate for the flapless technique, which the practitioners in this study follow as the majority felt confident using the flapless technique when the crestal bone width is at $6 \mathrm{~mm}$ or more.

Changing the location of the implant placement had no effect on the preference as the majority still preferred the flap technique, even though in the literature $[20,21]$ the use of the flapless technique has some benefits at the anterior region surgeries in avoiding the loss of bone and soft tissue. But choosing the flapless approach needs extra planning prior to the surgery, while the flap technique requires less planning [22]. Also for the practitioners felt more confident in using the flap technique for the multiple implant placements and in using the flapless technique for the single implant surgeries which can be justified by the high risk of clinician's errors in the angulation using the flapless technique as stated by Van de Velde, et al. [17].

The majority of the main advantages chosen by the participants were all related to the patient's well-being and the success of the implant, while the clinician's time and efforts had the least responses which shows that the preference of the majority of the clinician's is centered towards minimizing the patient's discomfort and to enhance the healing of the surgical site which follows the advantages of the technique stated by Tsoukaki, et al. [6].

\section{Conclusion}

With the choice of the flapless surgical technique; the frequency of requesting CBCTs and surgical guides increases, the practitioners feel confident using the flapless technique for single implant placement and to avoid hemorrhagic tendencies of patients on anticoagulants, and the main advantage observed by the practitioners is the reduced trauma to the patient, overall the flap surgical technique is still preferred by the practitioners over the flapless technique.

\section{References}

1. Vohra F, Habib R (2015) Knowledge and attitude of dentists toward implant retained restorations in Saudi Arabia. Niger J Clin Pract 18(3): 312-317.

2. Kinsel RP, Lamb RE, Moneim A (2000) Development of gingival esthetics in the edentulous patient with immediately loaded, single-stage, implant-supported fixed prostheses: a clinical report. Int J Oral Maxillofac Implants 15(5): 711-721.

3. Ozan 0, Turkyilmaz I, Yilmaz B (2007) A preliminary report of patients treated with early loaded implants using computerized tomography-guided surgical stents: flapless versus conventional flapped surgery. J Oral Rehabil 34(11): 835-840.

4. Ramfjord SF, Costich ER (1968) Healing after exposure of periosteum on the alveolar process. J Periodontol 39(4): 199-207.

5. Pisoni L, Ordesi P, Siervo P, Bianchi AE, Persia M, et al. (2016) Flapless Versus Traditional Dental Implant Surgery: Long-Term Evaluation of Crestal Bone Resorption. J Oral Maxillofac Surg 74(7): 1354-1359.

6. Tsoukaki M, Kalpidis CD, Sakellari D, Tsalikis L, Mikrogiorgis G, et al. (2013) Clinical, radiographic, microbiological, and immunological outcomes of flapped vs. flapless dental implants: a prospective randomized controlled clinical trial. Clin Oral Implants Res 24(9): 969-976.

7. Campelo LD, Camara JR (2002) Flapless implant surgery: a 10-year clinical retrospective analysis. Int J Oral Maxillofac Implants 17(2): 271-276.

8. Lemos CAA, Verri FR, Cruz RS, Gomes JML, Dos Santos DM, et al. (2018) Comparison between flapless and open-flap implant placement: a systematic review and meta-analysis. Int J Oral Maxillofac Surg.

9. KOSA MOH (2017) Statistical Book.

10. KOSA GAS (2016) Population in Riyadh region by gender, age groups and nationality (Saudis/ Non Saudis).

11. Ardawi MS, Sibiany AM, Bakhsh TM, Qari MH, Maimani AA (2012) High prevalence of vitamin D deficiency among healthy Saudi Arabian men: relationship to bone mineral density, parathyroid hormone, bone turnover markers, and lifestyle factors. Osteoporos Int 23(2): 675-686. 


\section{Open Access Journal of Dental Sciences}

12. Ghannam NN, Hammami MM, Bakheet SM, Khan BA (1999) Bone mineral density of the spine and femur in healthy Saudi females: relation to vitamin D status, pregnancy, and lactation. Calcif Tissue Int 65(1): 2328.

13. Ramalingam S, Habib SR, Sundar C, Dawas AB, AlRashed M, et al. (2017) Perceptions of dental interns in Saudi Arabia toward implant placement in medically compromised patients. J Educ Health Promot 6: 104.

14. Pani S, Al Shalan A, Al Saigh H, Shaheen R, Radwan V (2012) Saudi dental students perception of their education in Special Care Dentistry and its effect on their confidence to render care. Journal of Disability and Oral Health 13(1): 19-25.

15. Shi Q, Xu J, Zhang T, Zhang B, Liu H (2017) Postoperative Bleeding Risk in Dental Surgery for Patients on Oral Anticoagulant Therapy: A Meta-analysis of Observational Studies. Front Pharmacol 8: 58.

16. Zoman HA, Jetaily SA, Robert AA, Baskaradoss JK, AlSuwyed A, et al. (2013) Flapless Dental Implant Surgery for Patients on Oral Anticoagulants-The "WarLess Procedure": A Report of 2 Cases. Journal of Oral Implantology 39(1): 264-270.

17. Van De Velde T, Glor F, De Bruyn H (2008) A model study on flapless implant placement by clinicians with a different experience level in implant surgery. Clin Oral Implants Res 19(1): 66-72.

18. Wang F, Huang W, Zhang Z, Wang H, Monje A, et al. (2017) Minimally invasive flapless vs. flapped approach for single implant placement: a 2-year randomized controlled clinical trial. Clin Oral Implants Res 28(6): 757-764.

19. Llamas Monteagudo O, Girbes Ballester P, Vina Almunia J, Penarrocha Oltra D, Penarrocha Diago M (2017) Clinical parameters of implants placed in healed sites using flapped and flapless techniques: A systematic review. Med Oral Patol Oral Cir Bucal 22(5): 572-581.

20. Kan JY, Rungcharassaeng K, Ojano M, Goodacre C (2000) Flapless anterior implant surgery: a surgical and prosthodontic rationale. Pract Periodontics Aesthet Dent 12(5): 467-474.

21. Oh TJ, Shotwell J, Billy E, Byun HY, Wang HL (2007) Flapless implant surgery in the esthetic region: advantages and precautions. Int $\mathrm{J}$ Periodontics Restorative Dent 27(1): 27-33.

22. Romero Ruiz MM, Mosquera Perez R, Gutierrez Perez JL, Torres Lagares D (2015) Flapless implant surgery: A review of the literature and 3 case reports. J Clin Exp Dent 7(1): 146-152.

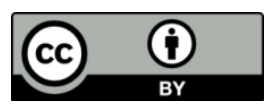

